This item was submitted to Loughborough's Research Repository by the author.

Items in Figshare are protected by copyright, with all rights reserved, unless otherwise indicated.

\title{
Sitting time and obesity in a sample of adults from Europe and the USA
}

\section{PLEASE CITE THE PUBLISHED VERSION}

http://dx.doi.org/10.1080/03014460.2016.1232749

\section{PUBLISHER}

(c) Taylor \& Francis

\section{VERSION}

AM (Accepted Manuscript)

\section{PUBLISHER STATEMENT}

This work is made available according to the conditions of the Creative Commons Attribution-NonCommercialNoDerivatives 4.0 International (CC BY-NC-ND 4.0) licence. Full details of this licence are available at: https://creativecommons.org/licenses/by-nc-nd/4.0/

\section{LICENCE}

CC BY-NC-ND 4.0

\section{REPOSITORY RECORD}

Bullock, Victoria E., Paula L. Griffiths, Lauren B. Sherar, and Stacy A. Clemes. 2019. "Sitting Time and Obesity in a Sample of Adults from Europe and the USA". figshare. https://hdl.handle.net/2134/22830. 
Sitting time and obesity in a sample of adults from Europe and the USA

Victoria E Bullock ${ }^{1}$, Paula Griffiths ${ }^{1}$, Lauren B Sherar ${ }^{1,2}$, Stacy A Clemes ${ }^{1,2}$

\section{Author affiliations:}

${ }^{1}$ School of Sport, Exercise and Health Sciences, Loughborough University, Loughborough, Leicestershire, LE11 3TU, UK.

${ }^{2}$ The NIHR Leicester-Loughborough Diet, Lifestyle and Physical Activity Biomedical Research Unit, Leicester, LE5 4PW.

\section{Corresponding author:}

Miss Victoria Bullock

Email: V.Bullock@lboro.ac.uk, Telephone: +44 (0)1509 223285

School of Sport, Exercise and Health Sciences, National Centre for Sport and Exercise Medicine, Loughborough University, Loughborough, Leicestershire, LE11 3TU, UK.

\section{Contact details for other authors:}

Dr Paula Griffiths: P.Griffiths@lboro.ac.uk

Dr Lauren B. Sherar: L.B.Sherar@lboro.ac.uk

Dr Stacy A. Clemes: S.A.Clemes@lboro.ac.uk

Keywords: Body Mass Index; International Physical Activity Questionnaire; Sedentary Behaviour 


\section{Abstract}

Background: Obesity is a risk factor for many chronic diseases and the prevalence is increasing worldwide. Research suggests that sedentary behaviour (sitting) may be related to obesity.

Aim: To examine the association between sitting time and obesity, while controlling for physical activity, in a large international sample.

Subjects and methods: 5338 adults from the UK, USA, Germany, Spain, Italy, France, Portugal, Austria and Switzerland self-reported their total daily sitting time, physical activity, age, height and weight. BMI $\left(\mathrm{kg} / \mathrm{m}^{2}\right)$, total physical activity (METminutes/week) and sitting time (hours/day) were derived. Participants were grouped into quartiles based on their daily sitting time $(<4,4-\leq 6,6-\leq 8$, and $>8$ hours/day) and logistic regression models explored the odds of being obese versus normal weight for each sitting time quartile.

Results: Participants in the highest sitting time quartile ( $\geq 8$ hours/day) had $62 \%$ higher odds of obesity compared to participants in the lowest quartile ( $<4$ hours/day) after adjustment for physical activity and other confounding variables (OR=1.62, 95\% $\mathrm{Cl}=1.24-2.12, \mathrm{p}<0.01)$

Conclusion: Sitting time is associated with obesity in adults, independent of physical activity. Future research should clarify this association using objective measures of sitting time and physical activity to further inform health guidelines. 


\section{Introduction}

Obesity is a risk factor for many leading causes of morbidity and mortality (Brown et al. 2005). In 2014, 600 million adults were classified as obese worldwide, which is more than double the prevalence in 1980 (World Health Organisation 2016). The medical costs associated with obesity have been estimated to increase by $£ 1.9-2$ billion/year in the UK and by \$48-66 billion/year in the USA by 2030 (Wang et al. 2011). Interventions are therefore needed to prevent the rise in obesity and its associated health and economic costs.

Obesity has generally been attributed to a chronic positive energy imbalance (Frayn 2003). Due to advances in technology, energy expenditure requirements of daily life have been greatly reduced (Egger, Vogels \& Westerterp 2001). Additionally, sedentary behaviours, defined as "any waking behaviour characterised by an energy expenditure $\leq 1.5$ metabolic equivalents (METs) while in a sitting or reclining posture" (Sedentary Behaviour Research Network 2012, p.540) have become ubiquitous in modern society. Accelerometer data from a UK study in 2014 showed that on average, office workers were sedentary for $68 \%$ of their waking hours on a workday and $60 \%$ of their waking hours on a non-workday (Clemes, O'Connell \& Edwardson 2014). Previous research has shown that high amounts of prolonged sedentary time are associated with numerous negative health outcomes, most notably all-cause mortality, type 2 diabetes, cardiovascular disease and some forms of cancer (Biswas et al. 2015; Wilmot et al. 2012).

Previous studies examining sedentary behaviour and obesity have used selfreported TV viewing time as a proxy for overall sedentary behaviour. Such studies have found a positive association with obesity (Williams, Raynor \& Ciccolo 2008). 
Additionally, other leisure-time sedentary behaviours, including computer use, have been associated with increased odds of being obese (Shields \& Tremblay 2008). Conversely, no association was found between leisure-time reading and obesity (Shields \& Tremblay 2008) and when all leisure-time sedentary behaviour is considered, some studies have found increased odds of obesity with increased sedentary time (Martinez-Gonzalez et al. 1999) while others have found no association (Banks et al. 2011). Mixed findings have also been observed in workplace studies with a review by van Uffelen and colleagues (2010) concluding that only five out of the ten cross-sectional studies looking at occupational sitting and Body Mass Index (BMI) found a positive association, four showed no association and one showed a negative association.

These domain specific findings only represent small proportions of the day and therefore, do not show the overall association between sedentary behaviour and obesity measures. Cross-sectional studies exploring total sedentary time in relation to obesity have found positive associations (Healy et al. 2008) and no association (Van Dyck et al. 2015) using accelerometer-determined sedentary time, and positive associations with self-reported sitting time (Santos et al. 2010). Prospective studies have also reported mixed results with studies finding positive (Mitchell et al. 2014), reverse (Pedisic et al. 2014), bidirectional (Golubic et al. 2015) and no association between sedentary time and obesity indicators measured by self-report (Mitchell et al. 2014; Pedisic et al. 2014) and accelerometry (Golubic et al. 2015).

Although the above studies have explored the relationship between overall sedentary time and obesity indicators, none have explored BMI as a categorical variable and looked at the odds of being obese in relation to sedentary time. Only two studies have examined this relationship. The first by Banks et al. (2011), found 
no association between self-reported total sitting time and obesity $\left(\geq 25 \mathrm{~kg} / \mathrm{m}^{2}\right)$ in a large sample of Thai university students and the second by Maher et al. (2013) also found no association between total accelerometer determined sedentary time and obesity in a sample of US adults. To date, no study has examined the relationship between total sedentary time and obesity in a large international sample. Therefore, the aim of this study was to investigate the association between self-reported sitting time (proxy for sedentary behaviour) and obesity, while controlling for physical activity, in a large sample of European and US adults.

\section{Methods}

\section{Participants}

The present study is based on a cross-sectional survey conducted in 2009 using convenience sampling. 9709 participants completed an online survey from nine different countries (UK, USA, Spain, Germany, Italy, Portugal, France, Austria, and Switzerland). The survey was created using online survey software (https://www.surveymonkey.com) and a link to the survey was embedded on a commercial website which was available in all respective countries in their native languages. The survey was disseminated further by the research team who also emailed the link to academic contacts in the respective countries. The present study only included participants aged 18 years or over. Participants were excluded if data were missing from gender, age, height or weight, physical activity or sitting time and participants with BMI values less than 14 or over $60 \mathrm{~kg} / \mathrm{m}^{2}$ were excluded (Miller 2003). Where reported country of residence was outside of the nine included countries $(n=95,1.8 \%)$ or was not reported $(n=221,4.1 \%)$, participants were 
included in the main analysis but excluded from between country analyses. After the data were cleaned, a total sample of 5338 participants was available for analyses (see Figure 1). The current study gained ethical approval from the Loughborough University Ethical Advisory Committee and participants provided informed consent prior to beginning the online survey.

Figure 1

\section{Measures}

\section{Socio-demographic variables}

Participants reported their age (18-24, 25-29, 30-39, 40-49, 50-59 or $\geq 60$ years), gender, country of residence, marital status (single, married, cohabitating, separated, divorced or widowed) and current occupation (full-time, part-time or student/unemployed).

\section{Obesity}

Self-reported height and weight were used to calculate BMI [(body weight $(\mathrm{kg})$ / height $(\mathrm{m})^{2}$ ] (American College of Sports Medicine 2013). A BMI of $<18.5 \mathrm{~kg} / \mathrm{m}^{2}$ was classified as underweight, $18.5-24.9 \mathrm{~kg} / \mathrm{m}^{2}$ as normal weight, $25-29.9 \mathrm{~kg} / \mathrm{m}^{2}$ as

overweight and $\geq 30 \mathrm{~kg} / \mathrm{m}^{2}$ as obese (NHLBI Obesity Education Initiative Expert Panel 1998).

\section{Sitting time and physical activity}

The self-administered, short version of the International Physical Activity Questionnaire (IPAQ)(2012) was included in the survey and was used to assess daily sitting time and physical activity. Thus, participants reported the amount of time 
spent sitting in hours and minutes on a typical weekday during the last 7 days. Furthermore, participants reported the frequency and duration of walking, moderate and vigorous intensity physical activities lasting for at least ten minutes, over the last 7 days. Data were processed according to the guidelines of the IPAQ scoring protocol (https://sites.google.com/site/theipaq/scoring-protocol) (IPAQ 2005) in which all physical activity data are summarised and expressed as total MET-minutes/week. This measure of physical activity was developed to facilitate international comparisons and the short form is recommended for large populations. The reliability and validity of the IPAQ has been reported to be comparable to other established self-report methods (Craig et al. 2003). Additionally, the sitting time question from the IPAQ has been used previously in epidemiological studies exploring sociodemographic predictors of sitting in international samples (Bauman et al. 2011).

\section{Statistical analysis}

Sitting time was categorised into four quartiles based on the median amount of sitting time for the sample (Quartile 1: $<4 \mathrm{hrs} / \mathrm{d}, 2: \geq 4-<6 \mathrm{hrs} / \mathrm{d}, 3: \geq 6-<8 \mathrm{hrs} / \mathrm{d}, 4$ : $\geq 8 \mathrm{hrs} / \mathrm{d})$.

Descriptive statistics were produced for the pooled sample. The median and interquartile ranges (IQR) were calculated for sitting and physical activity variables based on the recommendations from the IPAQ scoring protocol (IPAQ 2005). Due to the non-normal distribution and/or the categorisation of the data, non-parametric statistical tests explored the group differences and relationships between variables. These results then informed which confounding variables were included in the final regression analysis. Mann-Whitney tests were carried out to analyse differences in BMI, physical activity and sitting time between countries and genders. Significant 
differences in these groups for BMI category and obesity prevalence were assessed using the multi-dimensional chi-squared test. Kruskal-Wallis tests investigated the differences between age groups and BMI categories for the continuous variables of BMI, physical activity and sitting time. These were followed up by Mann-Whitney tests to analyse where the significance appeared within the groups. Correlations between BMI, physical activity, sitting time and age were analysed using Spearman's $r_{\mathrm{s}}$

Logistic regression models examined the association between sitting time and the odds of being obese compared to the reference group (normal BMI). Model 1 was unadjusted, Model 2 adjusted for physical activity and Model 3 adjusted for physical activity, age, gender, country of residence, marital status and current occupation. SPSS version 20 was used for all statistical analyses. Significance was defined as $p<0.05$ except for Mann-Whitney analyses following Kruskal-Wallis tests where correction was made to the $p$-value $(0.05)$ by dividing it by the number of comparisons.

\section{Results}

The majority of the sample were from the USA, UK and Germany (61.4\%), aged 3049 years $(55.7 \%)$, female $(67.2 \%)$, married $(44.4 \%)$ and in full-time occupations (61.1\%). The prevalence of obesity significantly differed between countries $(p<0.001)$ with the US sample having the highest prevalence (25.7\%) and the Italian sample, the lowest (9.2\%). Significant differences between countries were found for total physical activity $(p<0.001)$ with the Spanish sample having the highest median $(2586$ MET-minutes/week) and Portugal, the lowest (960 MET-minutes/week). Significant 
between country differences existed for sitting time $(p<0.001)$ with $29.5 \%$ of the US sample sitting for over 8 hours per day compared to $17.1 \%$ of the Spanish sample. See Supplementary Table I for descriptive characteristics stratified by country.

Table I shows the descriptive characteristics for the pooled sample as a whole, and when stratified by sitting time quartiles. The median BMI of the pooled sample was $24.8 \mathrm{~kg} / \mathrm{m}^{2}$ and the prevalence of obesity was $17 \%$ with a further $30.5 \%$ classified as overweight. The median total amount of physical activity was just over 2000 METminutes/week and ranged considerably (IQR=3358 MET-minutes/week). The median amount of time reported sitting per day was 360 minutes ( 6 hours) with the majority of participants sitting for 6-8 hours per day (30.8\%).

\section{Table I}

Physical activity level was inversely associated with BMI $\left(r_{s}=-0.09, p<0.01\right)$ and sitting time $\left(r_{s}=-0.33, p<0.01\right)$ whereas, sitting time was positively associated with BMI $\left(r_{s}=0.05, p<0.01\right)$. Participants who sat for $\geq 8 \mathrm{hrs} / \mathrm{d}$ had a higher BMI $(p<0.005)$, performed less total, vigorous, moderate and walking physical activity compared to participants in all other categories $(p<0.001)$.

Males had a higher median BMI than females $(p<0.001)$ but no significant gender differences were found for sitting time $(p>0.05)$. Age was positively associated with BMI $\left(r_{s}=0.25, p<0.01\right)$ and inversely related to sitting time $\left(r_{s}=-0.10, p<0.01\right)$. Adults in full-time occupations had a higher median BMI and sitting time compared to both those in part-time occupations $(p<0.01)$ and the students/unemployed $(p<0.01)$. Significant differences were found between marital status groups for BMI and sitting time $(p<0.0005)$ with single adults reporting the highest amount of sitting time and 
the lowest median BMI in comparison to all other groups. (See Supplementary Table II).

Logistic regression showed that adults in the highest category of sitting time had the highest odds of being obese compared to normal weight $(\mathrm{OR}=1.62,95 \% \mathrm{Cl}=1.24-$ 2.12, $p<0.01$ ) after controlling for total physical activity, gender, age, country of residence, marital status and current occupation (Table II). There were no significant differences between the middle quartiles of the sitting time variable and the reference group. The adjusted model reliably predicted odds of being obese versus normal weight (omnibus chi-square=322.60, $\mathrm{df}=27, \mathrm{p}<0.01$ ).

\section{Table II}

\section{Discussion}

This study aimed to clarify the association between total daily sitting time (used as a proxy for sedentary time) and obesity, in order to further inform health guidelines. High amounts of sitting time were associated with increased odds of being obese versus normal weight in the present sample from nine countries. Adults who reported sitting times of eight or more hours per day had $62 \%$ higher odds of being obese compared to the reference group ( $<4$ hours/day) after adjustment for physical activity, gender, age, country of residence, marital status and current occupation.

Only two previous studies (Banks et al. 2011; Maher et al. 2013) have analysed the association between total sedentary time and BMI-defined obesity, both focused on one nationality only and contrary to the current study found no association between sedentary time and obesity. Discrepancy in findings could be due to differences in the measurement tools and/or the population studied. For example, Banks and colleagues (2011) asked participants to report their typical amount of time per day 
spent sitting, whereas the current study measured total time reported sitting on a typical weekday. Research has found higher sitting times on workdays (i.e. weekdays) compared to non-workdays (i.e. weekends) (Clemes, O'Connell \& Edwardson. 2014). Additionally, the sample in this Thai study had a larger proportion of males (44.8\%) compared to the current study (32.8\%) and a lower obesity prevalence (21.8\% versus $24.8 \%$ in the current study). It should also be noted that the Asian cut-off point for obesity (BMI $\geq 25 \mathrm{~kg} / \mathrm{m}^{2}$ ) was used which may also have contributed to the difference in findings.

A potential reason for the discrepancy in findings with Maher and colleagues' (2013) study could be due to the difference in sedentary behaviour measures with the US study using accelerometry (<100 counts/min) as a proxy for sedentary behaviour compared to the self-report measure adopted in the current study. Consequently, Maher et al. documented over eight hours of sedentary time per day compared to a median of six hours per day found in the current study. Previous validation studies support this discrepancy by demonstrating the underreporting of sedentary time with self-report measures compared to accelerometer-determined sedentary time, especially when using a single-item question similar to the one adopted in the current study (Clemes et al. 2012). Furthermore, accelerometry cannot distinguish between sitting and standing (Atkin et al. 2012) thus, potentially producing larger sedentary time estimates as time spent standing still can be misinterpreted as sedentary time.

The results of the current study support previous studies using TV viewing as a proxy measure of sedentary time where associated increases of $70 \%$ in the odds of being obese have been observed with high amounts of sedentary behaviour (Shields \& Tremblay 2008). Additionally, when all screen-based entertainment (Stamatakis, 
Hirani \& Rennie 2009) and all leisure-time sedentary behaviour (Martinez-Gonzalez et al. 1999) is measured, an increase of $68 \%$ and $61 \%$ in the odds of being obese have been found in the highest category of sedentary time compared to the lowest respectively. A weaker but still significant association has been found between obesity and sedentary time at work with $\mathrm{Hu}$ (2003) observing a $25 \%$ increase in the odds of being obese for those in the highest category of occupational sedentary time compared to the lowest. Conversely, no association was with obesity found when leisure-time sitting excluding TV or video viewing was measured ( $\mathrm{Hu} 2003)$. Therefore, a combination of all of these domains of sedentary time on a weekday would produce a moderate increase in the odds of being obese similar to the findings of the current study.

A potential mechanism for the association between sitting time and obesity found in this study could be that sedentary behaviours displace physical activities thus, causing a reduction in energy expenditure (Mansoubi et al. 2014). The current study did find a positive association between obesity and sitting time after controlling for physical activity; however, physical activity was inversely associated with sitting time providing some evidence for this explanation.

The main aim of this study was to provide further evidence on the relationship between obesity and sedentary behaviour because most physical activity guidelines for adults do not consider sedentary time and for those that do (e.g. the UK, Department of Health 2011), no quantifiable reduction is stated (Kahlmeier et al. 2015). Therefore, evidence from this study suggests that high amounts of sedentary behaviour over eight hours per day do need to be reduced to decrease the associated odds of being obese. This threshold of eight hours per day of sitting time associated with increased odds of being obese is similar to previous studies 
examining all-cause mortality risk where a threshold of eight (Inoue et al. 2008) and ten hours (Bjork Petersen et al. 2014) per day of sitting time have been found. Additionally, this study supports the recent workplace guidelines stating that workers should aim to reduce their occupational sitting by at least two hours per day (Buckley et al. 2015).

The main limitation of this study was the use of convenience sampling which provided no information on the survey uptake and may have resulted in potential biases. For example, the sample was biased towards females $(67.2 \%)$ thus reducing the representativeness of the sample and generalizability of the findings. The overall obesity prevalence found in the current study (17\%) was similar to previous European studies [17\% (von Ruesten et al. 2011), 4-37\% (Berghofer et al. 2008)] but considerably lower compared to previous US studies [34\% (Flegal et al. 2010)]. The obesity prevalence in the US sample of the current study was higher than the pooled prevalence at $26 \%$ but still significantly lower than previous US studies. A potential reason for the difference in findings is that ethnicity was not consistently assessed in each country, thus could not be described or included in the final analyses. Therefore, the US sample may have underrepresented ethnicities with generally higher obesity rates for example non-Hispanic black men and women (Flegal et al. 2010). Further limitations include the categorisation of BMI to explore obesity odds leading to reduced statistical power (Altman \& Royston 2006) and the use of selfreport measures which are influenced by recall and social desirability bias (Atkin et al. 2012). Additionally, 45\% of participants were removed because they did not fully complete the survey which may have introduced possible bias impacting the results.

Conversely, this study has many strengths. The use of self-report measures allowed a large sample to be measured with low participant burden and the IPAQ is known to 
be an acceptable measure of physical activity and sedentary behaviour, specifically designed for population level research (Craig et al. 2003). This is supported by the current study reporting a median amount of sitting time similar to a previous large international study (Bauman et al. 2011). Furthermore, it is common in online surveys for large amounts of participants to be removed due to incomplete responses (Sánchez-Fernández, Muñoz-Leiva \& Montoro-Ríos 2012) and a large, sufficiently powered sample was still obtained.

\section{Conclusion}

The current study is the first to analyse the association between BMI-defined obesity and total sedentary behaviour in a sample comprising multiple nations. As a result, this study highlights that high amounts of sedentary behaviour are prevalent in different cultures and have the potential to negatively impact health. Furthermore, this study is one of the few to measure overall sedentary time in relation to BMIdefined obesity and the only study to find significantly increased odds of being obese compared to normal weight with high levels of sedentary time. Previous studies have shown this relationship with other measures of obesity such as waist circumference (Healy et al. 2008), further strengthening the evidence for a relationship between obesity and total sedentary behaviour. This demonstrates the importance of taking all sedentary behaviours into consideration and that targeting single domains of sedentary time may not reduce the associated health risks. Future research should focus on clarifying the relationship between total sedentary behaviour and obesity using objective measures and longitudinal designs in order to further inform health interventions and sedentary behaviour guidelines. 


\section{Declaration of interest}

The authors report no conflicts of interest. The original online survey was supported by Masai GB Limited (MBT). The company played no role in the study design, analyses, or in the preparation of this manuscript. Stacy Clemes and Lauren Sherar are supported by the National Institute for Health Research (NIHR) Diet, Lifestyle \& Physical Activity Biomedical Research Unit based at University Hospitals of Leicester and Loughborough University. The views expressed are those of the authors and not necessarily those of the NHS, the NIHR or the Department of Health. The work in this paper is part of the research portfolio supported by the NIHR Collaboration for Leadership in Applied Health Research and Care-East Midlands (NIHR CLAHRC for EM). 


\section{References}

Altman DG, Royston P. 2006. The cost of dichotomising continuous variables. BMJ. 332(7549):1080.

American College of Sports Medicine, 2013. ACSM's guidelines for exercise testing and prescription, 8th ed. London, Lippincott Williams \& Wilkins.

Atkin AJ, Gorely T, Clemes SA, Yates T, Edwardson C, Brage S, Salmon J, Marshall SJ, Biddle SJ. 2012. Methods of measurement in epidemiology: Sedentary behaviour. Int J Epidemiol. 41(5):1460-1471.

Banks E, Lim L, Seubsman SA, Bain C, Sleigh A. 2011. Relationship of obesity to physical activity, domestic activities, and sedentary behaviours: Cross-sectional findings from a national cohort of over 70,000 Thai adults. BMC Public Health. 11:762.

Bauman A, Ainsworth BE, Sallis JF, Hagströmer M, Craig CL, Bull FC, Pratt $M$, Venugopal K, Chau J, Sjöström M, IPS Group. 2011.The descriptive epidemiology of sitting: A 20-country comparison using the international physical activity questionnaire (IPAQ). Am J Prev Med. 41(2):228-235.

Berghofer A, Pischon T, Reinhold T, Apovian CM, Sharma AM, Willich SN. 2008. Obesity prevalence from a European perspective: A systematic review. BMC Public Health. 8:200.

Biswas A, Oh PI, Faulkner GE, Bajaj RR, Silver MA, Mitchell MS, Alter DA. 2015. Sedentary time and its association with risk for disease incidence, mortality, and 
hospitalization in adults: A systematic review and meta-analysis. Ann Intern Med. 162(2):123-132.

Bjork Petersen C, Bauman A, Gronbaek M, Wulff Helge J, Thygesen LC, Tolstrup JS. 2014. Total sitting time and risk of myocardial infarction, coronary heart disease and all-cause mortality in a prospective cohort of Danish adults. Int J Behav Nutr Phys Act. 11(1):13.

Brown WJ, Williams L, Ford JH, Ball K, Dobson AJ. 2005. Identifying the energy gap: Magnitude and determinants of 5-year weight gain in midage women. Obes Res. 13(8):1431-1441.

Buckley JP, Hedge A, Yates T, Copeland RJ, Loosemore M, Hamer M, Bradley G, Dunstan D. 2015. The sedentary office: An expert statement on the growing case for change towards better health and productivity. Br J Sports Med. 49(21):1357-1362.

Clemes SA, David BM, Zhao Y, Han X, Brown WJ. 2012. Validity of two self-report measures of sitting time. J Phys Act Health. 9:533-539.

Clemes SA, O'Connell SE, Edwardson CL. 2014. Office workers' objectively measured sedentary behavior and physical activity during and outside working hours. J Occup Environ Med. 56(3):298-303.

Craig CL, Marshall AL, Sjostrom M, Bauman AE, Booth ML, Ainsworth BE, Pratt M, Ekelund U, Yngve A, Sallis JF, Oja P. 2003. International physical activity questionnaire: 12-country reliability and validity. Med Sci Sports Exerc. 35(8):13811395. 
Department of Health. 2011. UK physical activity guidelines. Available online at: https://www.gov.uk/government/publications/uk-physical-activity-guidelines, accessed 12 July 2016.

Egger GJ, Vogels N, Westerterp KR. 2001. Estimating historical changes in physical activity levels. Med J Aust. 175(11-12):635-636.

Flegal KM, Carroll MD, Ogden CL, Curtin LR. 2010. Prevalence and trends in obesity among US adults, 1999-2008. JAMA. 303(3):235-241.

Frayn SA, 2003. Metabolic regulation: A human perspective, 2nd ed. Oxford, Blackwell Science Ltd.

Golubic R, Wijndaele K, Sharp S, Simmons RK, Griffin SJ, Wareham NJ, Ekelund U, Brage S, ProActive Study Group. 2015. Physical activity, sedentary time and gain in overall and central body fat: 7-year follow-up of the ProActive trial cohort. Int J Obes. 39:142-148.

Healy GN, Wijndaele K, Dunstan DW, Shaw JE, Salmon J, Zimmet PZ. Owen N. 2008. Objectively measured sedentary time, physical activity, and metabolic risk: the Australian Diabetes, Obesity and Lifestyle Study (AusDiab). Diabetes care. 31(2):369-371.

Hu FB. 2003. Sedentary lifestyle and risk of obesity and type 2 diabetes. Lipids. 38(2):103-108.

Inoue $\mathrm{M}$, Iso H, Yamamoto S, Kurahashi N, Iwassaki M, Sasazuki S, Tsugane S, Japan Public Health Centre-Based Prospective Study Group. 2008. Daily total physical activity level and premature death in men and women: Results from a large- 
scale population-based cohort study in japan (JPHC study). Ann Epidemiol. 18(7):522-530.

IPAQ. 2012. Downloadable questionnaires. Available online at: https://sites.google.com/site/theipaq/questionnaire_links, accessed 12 July 2016.

IPAQ. 2005. IPAQ scoring protocol. Available online at: https://sites.google.com/site/theipaq/scoring-protocol, accessed 12 July 2016.

Kahlmeier S, Wijnhoven TM, Alpiger P, Schweizer C, Breda J, Martin BW. 2015. National physical activity recommendations: Systematic overview and analysis of the situation in European countries. BMC Public Health. 15(1):1.

Maher CA, Mire E, Harrington DM, Staiano AE, Katzmarzyk PT. 2013. The independent and combined associations of physical activity and sedentary behavior with obesity in adults: NHANES 2003-06. Obesity. 21(12):E730-E737.

Mansoubi M, Pearson N, Biddle SJ, Clemes S. 2014. The relationship between sedentary behaviour and physical activity in adults: A systematic review. Prev Med. 69:28-35.

Martinez-Gonzalez MA, Martinez JA, Hu FB, Gibney MJ, Kearney J. 1999. Physical inactivity, sedentary lifestyle and obesity in the European Union. Int $\mathrm{J}$ Obes Relat Metab Disord. 23(11):1192-1201.

Miller Y. 2003. Recommendations for the truncation of body mass index in population data. NSW Centre for Physical Activity and Health. CPAH03-0005. 
Mitchell JA, Bottai M, Park Y, Marshall SJ, Moore SC, Matthews CE. 2014. A prospective study of sedentary behavior and changes in the body mass index distribution. Med Sci Sports Exerc. 46(12):2244-2252.

NHLBI Obesity Education Initiative Expert Panel. 1998. Executive summary of the clinical guidelines on the identification, evaluation, and treatment of overweight and obesity in adults. Arch Intern Med. 158:1855-1867.

Pedisic Z, Grunseit A, Ding D, Chau JY, Banks E, Stamatakis E, Jalaludin BB, Bauman AE. 2014. High sitting time or obesity: Which came first? bidirectional association in a longitudinal study of 31,787 Australian adults. Obesity (Silver Spring). 22(10):2126-2130.

Sánchez-Fernández J, Muñoz-Leiva F, Montoro-Ríos FJ. 2012. Improving retention rate and response quality in web-based surveys. Comput Hum Behav. 28(2):507514.

Santos R, Soares-Miranda L, Vale S, Moreira C, Marques AI, Mota J. 2010. Sitting time and body mass index, in a Portuguese sample of men: Results from the Azorean Physical Activity and Health Study (APAHS). Int J Environ Res Public Health. 7(4):1500-1507.

Sedentary Behaviour Research Network. 2012. Letter to the editor: Standardized use of the terms "sedentary" and "sedentary behaviours". Appl Physiol Nutr Metab. 37(3):540-542.

Shields M, Tremblay MS. 2008. Sedentary behaviour and obesity. Health Rep. 19(2):19-30. 
Stamatakis E, Hirani V, Rennie K. 2009. Moderate-to-vigorous physical activity and sedentary behaviours in relation to body mass index-defined and waist circumference-defined obesity. Br J Nutr. 101(05):765-773.

Van Dyck D, Cerin E, De Bourdeaudhuij I, Hinckson E, Reis RS, Davey R, Sarmiento OL, Mitas J, Troelsen J, MacFarlane D, Salvo D, Aguinaga-Ontoso I, Owen N, Cain KL, Sallis JF. 2015. International study of objectively measured physical activity and sedentary time with body mass index and obesity: IPEN adult study. Int J Obes (Lond). 39(2):199-207.

van Uffelen JGZ, Wong J, Chau JY, van der Ploeg HP, Riphagen I, Gilson ND, Burton NW, Healy GN, Thorp AA, Clark BK, Dunstan DW, Bauman A, Owen N, Brown WJ. 2010. Occupational sitting and health risks: A systematic review. Am J Prev Med. 39(4):379-388.

von Ruesten A, Steffen A, Floegel A, van der A DL, Masala G, Tjønneland A, Halkjaer J, Palli D, Wareham NJ, Loos RJF, Sørensen TIA, Boeing H. 2011. Trend in obesity prevalence in european adult cohort populations during follow-up since 1996 and their predictions to 2015. PLoS One. 6(11):e27455.

Wang YC, McPherson K, Marsh T, Gortmaker SL, Brown M. 2011. Health and economic burden of the projected obesity trends in the USA and the UK. Lancet. 378(9793):815-825.

Williams DM, Raynor HA, Ciccolo JT. 2008. A review of TV viewing and its association with health outcomes in adults. Am J Lifestyle Med. 2(3):250-259. 
Wilmot EG, Edwardson CL, Achana FA, Davies MJ, Gorely T, Gray LJ, Khunti K, Yates T, Biddle SJ. 2012. Sedentary time in adults and the association with diabetes, cardiovascular disease and death: Systematic review and meta-analysis. Diabetologia. 55(11):2895-2905.

World Health Organisation. 2016. Media centre: Obesity and overweight (fact sheet $\mathrm{N}^{0}$ 311). Available online at: http://www.who.int/mediacentre/factsheets/fs311/en/, accessed 12 July 2016. 


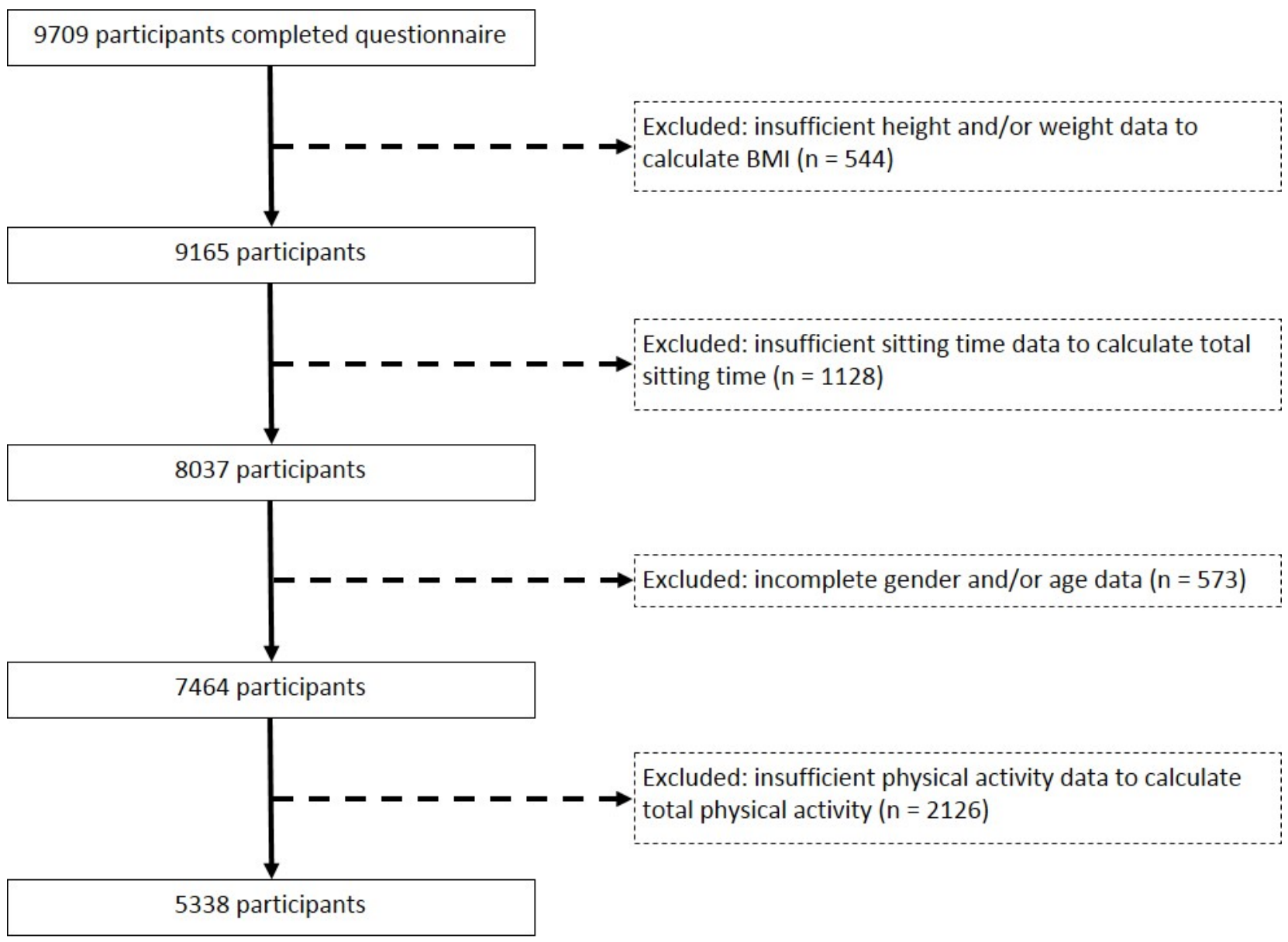

Figure 1: Flow diagram of participant exclusion prior to statistical analysis 
Table I: Descriptive characteristics of the pooled sample stratified by sitting time quartiles

\begin{tabular}{|c|c|c|c|c|c|c|}
\hline & & \multirow[t]{2}{*}{ Total } & \multicolumn{4}{|c|}{ Sitting time Quartile } \\
\hline & & & $<4 \mathrm{hrs} / \mathrm{d}$ & $\begin{array}{c}\geq 4-<6 \\
\text { hrs/d }\end{array}$ & $\begin{array}{c}\geq 6-<8 \\
\text { hrs/d }\end{array}$ & $\geq 8 \mathrm{hrs} / \mathrm{d}$ \\
\hline Total (\% [n]) & & $\begin{array}{c}100.0 \\
(5338)\end{array}$ & $\begin{array}{c}20.0 \\
(1067)\end{array}$ & $\begin{array}{c}24.8 \\
(1323)\end{array}$ & $\begin{array}{c}30.8 \\
(1646)\end{array}$ & $\begin{array}{c}24.4 \\
(1302)\end{array}$ \\
\hline Female (\%) & & 67.2 & 68.3 & 66.5 & 65.5 & 69.1 \\
\hline \multirow[t]{6}{*}{ Age group (\%) * } & $18-24$ years & 8.2 & 5.9 & 9.8 & 8.4 & 8.2 \\
\hline & 25-29 years & 11.6 & 8.5 & 10.0 & 11.1 & 16.4 \\
\hline & 30-39 years & 28.2 & 29.8 & 25.2 & 27.6 & 30.4 \\
\hline & 40-49 years & 27.5 & 29.5 & 26.2 & 28.7 & 25.7 \\
\hline & $50-59$ years & 17.4 & 17.7 & 18.6 & 17.7 & 15.4 \\
\hline & $\geq 60$ years & 7.1 & 8.5 & 10.1 & 6.5 & 3.8 \\
\hline \multirow[t]{7}{*}{ Marital Status (\%) * } & Single & 27.0 & 19.2 & 24.6 & 27.7 & 34.9 \\
\hline & Married & 44.4 & 52.5 & 48.6 & 41.2 & 39.8 \\
\hline & Cohabiting & 13.5 & 11.3 & 12.5 & 14.2 & 16.1 \\
\hline & Separated & 1.3 & 1.4 & 1.4 & 1.1 & 1.3 \\
\hline & Divorced & 4.8 & 4.3 & 5.2 & 5.0 & 4.8 \\
\hline & Widowed & 1.0 & 0.8 & 0.9 & 1.2 & 0.8 \\
\hline & Not stated & 8.0 & 10.4 & 6.8 & 9.7 & 5.8 \\
\hline
\end{tabular}




\begin{tabular}{|c|c|c|c|c|c|c|}
\hline \multirow[t]{4}{*}{ Occupation (\%) * } & Full-time & 61.1 & 68.0 & 52.5 & 63.7 & 72.0 \\
\hline & Part-time & 18.4 & 18.2 & 22.2 & 18.1 & 12.0 \\
\hline & $\begin{array}{c}\text { Student/ } \\
\text { unemployed }\end{array}$ & 19.4 & 12.4 & 24.3 & 17.4 & 15.1 \\
\hline & Not stated & 1.1 & 1.3 & 1.0 & 0.7 & 0.9 \\
\hline BMI $\left(\mathrm{kg} / \mathrm{m}^{2}\right)$ * & Median (IQR) & 24.8 & 24.4 & 24.8 & 24.6 & 25.1 \\
\hline & & (6.1) & $(5.6)$ & $(6.0)$ & $(6.0)$ & (6.6) \\
\hline \multirow[t]{4}{*}{ BMI category (\%) * } & Underweight & 2.1 & 2.0 & 2.1 & 2.5 & 1.5 \\
\hline & Normal weight & 50.5 & 53.8 & 50.3 & 51.3 & 47.0 \\
\hline & Overweight & 30.5 & 29.5 & 32.2 & 29.5 & 30.7 \\
\hline & Obese & 17.0 & 14.7 & 15.3 & 16.7 & 20.7 \\
\hline $\begin{array}{l}\text { Walking PA (MET- } \\
\text { minutes/week)* }\end{array}$ & Median (IQR) & $\begin{array}{c}792.0 \\
(1254.0)\end{array}$ & $\begin{array}{c}1386.0 \\
(2277.0)\end{array}$ & $\begin{array}{c}1039.5 \\
(2079.0)\end{array}$ & $\begin{array}{c}693.0 \\
(1056.0)\end{array}$ & $\begin{array}{l}528.0 \\
(990.0)\end{array}$ \\
\hline $\begin{array}{l}\text { Moderate PA (MET- } \\
\text { minutes/week) * }\end{array}$ & Median (IQR) & $\begin{array}{l}240.0 \\
(720.0)\end{array}$ & $\begin{array}{c}360.0 \\
(1200.0)\end{array}$ & $\begin{array}{c}240.0 \\
(960.0)\end{array}$ & $\begin{array}{c}240.0 \\
(720.0)\end{array}$ & $\begin{array}{c}40.0 \\
(480.0)\end{array}$ \\
\hline $\begin{array}{c}\text { Vigorous PA (MET- } \\
\text { minutes/week) * }\end{array}$ & Median (IQR) & $\begin{array}{c}320.0 \\
(1440.0)\end{array}$ & $\begin{array}{c}960.0 \\
(2400.0)\end{array}$ & $\begin{array}{c}480.0 \\
(1920.0)\end{array}$ & $\begin{array}{c}320.0 \\
(1440.0)\end{array}$ & $\begin{array}{c}0.0 \\
(720.0)\end{array}$ \\
\hline $\begin{array}{l}\text { Total PA (MET- } \\
\text { minutes/week) * }\end{array}$ & Median (IQR) & $\begin{array}{c}2079.0 \\
(3358.1)\end{array}$ & $\begin{array}{l}3672.0 \\
(6228.0)\end{array}$ & $\begin{array}{l}2754.0 \\
(4296.0)\end{array}$ & $\begin{array}{l}1945.0 \\
(2799.3)\end{array}$ & $\begin{array}{l}1386.0 \\
(1808.3)\end{array}$ \\
\hline $\begin{array}{c}\text { Sitting time } \\
\text { (minutes/day) * }\end{array}$ & Median (IQR) & $\begin{array}{l}360.0 \\
(240.0)\end{array}$ & $\begin{array}{l}135.0 \\
(60.0)\end{array}$ & $\begin{array}{l}300.0 \\
(60.0)\end{array}$ & $\begin{array}{c}420.0 \\
(120.0)\end{array}$ & $\begin{array}{r}600.0 \\
(120.0)\end{array}$ \\
\hline
\end{tabular}

* Significant difference between sitting time quartiles $(p<0.05), P A=$ physical activity 
Table II. Associations between sitting time (ST) and obesity in the pooled sample ( $n=3256,26.4 \%$ obese)

\begin{tabular}{|c|c|c|c|c|}
\hline & & Model 1† OR (95\% Cl) & Model 2‡ OR $(95 \% \mathrm{Cl})$ & Model 3T OR (95\% Cl) \\
\hline ST quartile & $\%$ Obese (n) & & & \\
\hline$<4 \mathrm{hrs} / \mathrm{d}$ & $22.9(147)$ & 1 (ref.) & 1 (ref.) & 1 (ref.) \\
\hline $4-<6 \mathrm{hrs} / \mathrm{d}$ & $24.0(192)$ & $1.06(0.83-1.36)$ & $1.06(0.83-1.36)$ & $1.07(0.83-1.39)$ \\
\hline $6-<8 \mathrm{hrs} / \mathrm{d}$ & $26.3(262)$ & $1.20(0.96-1.52)$ & $1.19(0.94-1.52)$ & $1.23(0.95-1.58)$ \\
\hline$\geq 8 \mathrm{hrs} / \mathrm{d}$ & $31.5(257)$ & $1.55^{\star}(1.23-1.96)$ & $1.53^{*}(1.20-1.96)$ & $1.62^{*}(1.24-2.12)$ \\
\hline $\mathrm{p}$ (trend) & & $0.001^{*}$ & $0.002^{*}$ & $0.001^{*}$ \\
\hline
\end{tabular}

† unadjusted model, $\ddagger$ adjusted for physical activity, $\uparrow$ adjusted for physical activity, gender, age, country of residence, marital status and current occupation. ${ }^{*} \mathrm{p}<0.01$. OR= odds ratio, $\mathrm{Cl}=$ confidence interval. 
Supplementary Table I: Descriptive characteristics stratified by country

\begin{tabular}{|c|c|c|c|c|c|c|c|c|c|c|}
\hline & $\begin{array}{c}\text { Total } \\
(n=5338) \uparrow\end{array}$ & $\begin{array}{c}\text { UK } \\
(n=1107, \\
20.7 \%)\end{array}$ & $\begin{array}{c}\text { USA } \\
(n=1120 \\
21.0)\end{array}$ & $\begin{array}{c}\text { Germany } \\
(n=1171, \\
21.9 \%)\end{array}$ & $\begin{array}{c}\text { Spain } \\
(n=630, \\
11.8 \%)\end{array}$ & $\begin{array}{c}\text { Italy } \\
(n=425, \\
8.0 \%)\end{array}$ & $\begin{array}{c}\text { France } \\
(n=23, \\
0.4 \%)\end{array}$ & $\begin{array}{c}\text { Switzerland } \\
\qquad \begin{array}{c}(\mathrm{n}=89 \\
1.7 \%)\end{array}\end{array}$ & $\begin{array}{c}\text { Portugal } \\
(n=232 \\
4.3 \%)\end{array}$ & $\begin{array}{c}\begin{array}{c}\text { Austria } \\
(n=225, \\
4.2 \%)\end{array}\end{array}$ \\
\hline \multicolumn{11}{|l|}{ Gender (\%) } \\
\hline Male & 32.8 & 24.2 & 21.8 & 37.1 & 41.3 & 48.9 & 30.4 & 38.2 & 34.9 & 47.6 \\
\hline Female & 67.2 & 75.8 & 78.2 & 62.9 & 58.7 & 51.1 & 69.6 & 61.8 & 65.1 & 52.4 \\
\hline \multicolumn{11}{|c|}{ Age group (\%) } \\
\hline 18-24 years & 8.2 & 13.0 & 12.5 & 4.5 & 3.7 & 2.4 & 13.0 & 2.2 & 11.2 & 6.7 \\
\hline $25-29$ years & 11.6 & 12.7 & 13.3 & 12.6 & 6.5 & 6.1 & 4.3 & 11.2 & 18.5 & 12.9 \\
\hline 30-39 years & 28.2 & 26.5 & 21.2 & 29.5 & 34.9 & 2.9 & 47.8 & 34.8 & 39.7 & 29.8 \\
\hline 40-49 years & 27.5 & 22.9 & 19.2 & 32.6 & 34.4 & 40.2 & 21.7 & 29.2 & 18.5 & 30.7 \\
\hline $50-59$ years & 17.4 & 17.9 & 24.1 & 14.3 & 16.2 & 16.2 & 8.7 & 13.5 & 9.1 & 12.9 \\
\hline$\geq 60$ years & 7.1 & 7.0 & 9.7 & 6.6 & 4.3 & 6.1 & 4.3 & 9.0 & 3.0 & 7.1 \\
\hline \multicolumn{11}{|c|}{ Ethnicity (\%) } \\
\hline White & 88.9 & 90.4 & 82.0 & 94.3 & 2.1 & 76.7 & 30.4 & 75.3 & 94.4 & 94.7 \\
\hline Mixed & 7.0 & 2.7 & 15.1 & 1.3 & 0.0 & 23.0 & 0.0 & 1.1 & 2.2 & 0.4 \\
\hline Asian & 2.3 & 5.3 & 0.2 & 3.1 & 0.0 & 0.0 & 0.0 & 4.5 & 2.2 & 2.2 \\
\hline Black & 0.2 & 0.9 & 0.3 & 0.0 & 0.0 & 0.0 & 4.3 & 0.0 & 0.0 & 0.0 \\
\hline Other & 0.8 & 0.6 & 1.7 & 0.0 & 0.0 & 0.0 & 0.0 & 9.0 & 0.4 & 1.8 \\
\hline
\end{tabular}


Not stated

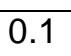

0.2

0.0

1.3

97.9

0.3

65.3

10.1

0.8

0.9

Marital status (\%)

Single

Married

Cohabiting

Separated

Divorced

Widowed

Not stated

$27.0 \quad 29$

$44.4 \quad 43.6$

32.4

22.8

30.6

1.2

21.7

27.0

47.4

47.2

36.2

24.0

$13.5 \quad 18.1$

7.7

20.8

10.2

0.0

34.8

1.3

1.9

1.5

1.0

1.9

3.5

1.0

0.3

8.0

0.4

0.1

0.0

Occupation (\%)

Full-time

Part-time

Student/unemployed

18.4

19.4

1.1

24.8

(6.1)

58.5

59.8

65.3

70.8

76.5

69.6

53.9

28.1

15.7

2.2

24.2

BMI $\left(\mathrm{kg} / \mathrm{m}^{2}\right)^{*}$

Median (IQR)

BMI category (\%)*

Underweight

Normal weight
2.1

50.5

11.3

18.4

12.1

129

13.0

1.7

1.7

$0.5 \quad 0.0$

$\begin{array}{lll}24.4 & 23.5 & 24.9\end{array}$

(5.1) (4.8) (6.8)

(4.6)

10.3

0.0

1.8

25.3

(6.4)

(7.7)

(5.8)

$\begin{array}{ll}2.8 & 0.0 \\ 63.8 & 52.2\end{array}$

3.4

1.7

56.2

62.1

43.8

46.0

56.0

63.8




\begin{tabular}{|c|c|c|c|c|c|c|c|c|c|c|}
\hline Overweight & 30.5 & 31.6 & 28.1 & 33.2 & 30.6 & 24.2 & 30.4 & 33.7 & 30.6 & 34.7 \\
\hline Obese & 17.0 & 17.1 & 25.7 & 19.1 & 11.7 & 9.2 & 17.4 & 6.7 & 5.6 & 14.2 \\
\hline $\begin{array}{l}\text { Vigorous PA† } \\
\text { Median (IQR) }\end{array}$ & $\begin{array}{c}320.0 \\
(1440.0)\end{array}$ & $\begin{array}{c}0.0 \\
(960.0)\end{array}$ & $\begin{array}{c}240.0 \\
(1440.0)\end{array}$ & $\begin{array}{c}80.0 \\
(1440.0)\end{array}$ & $\begin{array}{l}1080.0 \\
(2160.0)\end{array}$ & $\begin{array}{c}720.0 \\
(1440.0)\end{array}$ & $\begin{array}{c}480.0 \\
(1440.0)\end{array}$ & $\begin{array}{c}240.0 \\
(1320.0)\end{array}$ & $\begin{array}{c}0.0 \\
(720.0)\end{array}$ & $\begin{array}{c}0.0 \\
(1920.0)\end{array}$ \\
\hline $\begin{array}{l}\text { Moderate PA } \dagger \\
\text { Median (IQR) }\end{array}$ & $\begin{array}{l}240.0 \\
(720.0)\end{array}$ & $\begin{array}{c}0.0 \\
(480.0)\end{array}$ & $\begin{array}{l}240.0 \\
(720.0)\end{array}$ & $\begin{array}{c}360.0 \\
(1080.0)\end{array}$ & $\begin{array}{l}480.0 \\
(960.0)\end{array}$ & $\begin{array}{l}360.0 \\
(720.0)\end{array}$ & $\begin{array}{c}40.0 \\
(720.0)\end{array}$ & $\begin{array}{c}480.0 \\
(1160.0)\end{array}$ & $\begin{array}{c}0.0 \\
(360.0)\end{array}$ & $\begin{array}{l}280.0 \\
(960.0)\end{array}$ \\
\hline $\begin{array}{l}\text { Total PA† Median } \\
\text { (IQR)* }\end{array}$ & $\begin{array}{c}2079.0 \\
(3358.1)\end{array}$ & $\begin{array}{c}1710.0 \\
(2226.0)\end{array}$ & $\begin{array}{c}1893.0 \\
(3025.0)\end{array}$ & $\begin{array}{c}2586.0 \\
(5073.0)\end{array}$ & $\begin{array}{c}2910.0 \\
(3579.0)\end{array}$ & $\begin{array}{c}2466.0 \\
(3396.0)\end{array}$ & $\begin{array}{c}1727.5 \\
(2941.5)\end{array}$ & $\begin{array}{c}2148.0 \\
(3846.0)\end{array}$ & $\begin{array}{c}960.0 \\
(1977.0)\end{array}$ & $\begin{array}{c}2346.0 \\
(4445.0)\end{array}$ \\
\hline $\begin{array}{l}\text { Sitting time } \neq \\
\text { Median (IQR)* }\end{array}$ & $\begin{array}{l}360.0 \\
(240.0)\end{array}$ & $\begin{array}{c}360.0 \\
(300.0)\end{array}$ & $\begin{array}{l}420.0 \# \\
(360.0)\end{array}$ & $\begin{array}{l}360.0 \\
(288.0)\end{array}$ & $\begin{array}{c}300.0 \\
(300.0)\end{array}$ & $\begin{array}{c}360.0 \\
(285.0)\end{array}$ & $\begin{array}{c}300.0 \\
(240.0)\end{array}$ & $\begin{array}{c}360.0 \\
(300.0)\end{array}$ & $\begin{array}{l}300.0 \\
(285.0)\end{array}$ & $\begin{array}{c}360.0 \\
(240.0)\end{array}$ \\
\hline$\geq 6-<8 \mathrm{hrs} / \mathrm{d}$ & 30.8 & 31.2 & 31.8 & 27.6 & 31.3 & 36.7 & 26.1 & 30.3 & 24.6 & 32.0 \\
\hline$\geq 8 \mathrm{hrs} / \mathrm{d}$ & 24.4 & 27.8 & 29.5 & 25.5 & 17.1 & 17.2 & 21.7 & 23.6 & 23.3 & 21.8 \\
\hline
\end{tabular}


Supplementary Table II: Median (interquartile range) values for Body Mass Index (BMI), physical activity (PA) and sitting time stratified by gender, age group, BMI category, current occupation and marital status.

\begin{tabular}{|c|c|c|c|c|c|c|}
\hline & BMI $\left(\mathrm{kg} / \mathrm{m}^{2}\right)$ & $\begin{array}{c}\text { Walking PA (MET- } \\
\text { minutes/week) }\end{array}$ & $\begin{array}{l}\text { Moderate PA (MET- } \\
\text { minutes/week) }\end{array}$ & $\begin{array}{l}\text { Vigorous PA (MET- } \\
\text { minutes/week) }\end{array}$ & $\begin{array}{l}\text { Total PA (MET- } \\
\text { minutes/week) }\end{array}$ & $\begin{array}{c}\text { Sitting time } \\
\text { (minutes/day) }\end{array}$ \\
\hline \multicolumn{7}{|l|}{ Gender } \\
\hline Males & $25.6(4.8)$ & $825.0(1452.0)$ & $264.0(960.0)$ & $720.0(1920.0)$ & $2544.0(4035.0)$ & $360.0(240.0)$ \\
\hline \multicolumn{7}{|l|}{ Age group } \\
\hline $25-29$ years & $23.4(4.6)$ & $792.0(1782.0)$ & $240.0(720.0)$ & $480.0(1440.0)$ & $2148.0(3756.0)$ & $420.0(300.0)$ \\
\hline 30-39 years & $24.5(5.8)$ & $693.0(1320.0)$ & $240.0(720.0)$ & $480.0(1440.0)$ & $2095.0(3432.0)$ & $360.0(300.0)$ \\
\hline 40-49 years & $25.2(5.9)$ & $808.5(1056.0)$ & $240.0(800.0)$ & $360.0(1440.0)$ & $2118.0(3402.8)$ & $360.0(240.0)$ \\
\hline \multicolumn{7}{|l|}{ BMI category } \\
\hline Underweight & $17.9(1.0)$ & $1188.0(2338.9)$ & $300.0(720.0)$ & $440.0(1920.0)$ & $2361.0(4596.8)$ & $360.0(240.0)$ \\
\hline Normal weight & $22.5(2.8)$ & 891.0 (1270.5) & $240.0(820.0)$ & $480.0(1440.0)$ & $2274.0(3495.0)$ & $360.0(240.0)$ \\
\hline Overweight & $27.1(2.4)$ & 742.5 (1188.0) & $240.0(720.0)$ & $240.0(1440.0)$ & $2026.3(3303.8)$ & $360.0(240.0)$ \\
\hline Obese & $33.3(5.2)$ & 742.5) (1386.0) & $0.0(720.0)$ & $0.0(960.0)$ & 1702.5 (3273.0) & $360.0(360.0)$ \\
\hline
\end{tabular}

Occupation 


$\begin{array}{lcccccc}\text { Full-time } & 25.0(5.8) & 792.0(1254.0) & 240.0(720.0) & 480.0(1440.0) & 2172.0(3516.0) & 420.0(300.0) \\ \text { Part-time } & 24.2(5.9) & 693.0(1485.0) & 120.0(720.0) & 0.0(1440.0) & 1795.0(3369.0) & 300.0(240.0) \\ \text { Student/unemployed } & 24.2(6.8) & 825.0(1089.0) & 240.0(720.0) & 240.0(1440.0) & 2079.0(3039.75) & 300.0(240.0) \\ \text { Marital Status } & & & & & & \\ \text { Single } & 23.7(5.8) & 693.0(1089.0) & 240.0(720.0) & 480.0(1800.0) & 2079.0(3236.0) & 420.0(300.0) \\ \text { Married } & 25.6(6.2) & 825.0(1361.3) & 240.0(840.0) & 160.0(1440.0) & 2079.0(3565.5) & 300.0(240.0) \\ \text { Cohabiting } & 24.1(5.6) & 808.5(1650.0) & 240.0(720.0) & 240.0(1440.0) & 1980.0(3319.6) & 360.0(300.0) \\ \text { Separated } & 25.6(6.9) & 907.5(891.0) & 300.0(720.0) & 420.0(1170.0) & 1854.0(2681.6) & 330.0(240.0) \\ \text { Divorced } & 25.3(6.30 & 858.0(2004.8) & 240.0(960.0) & 240.0(1440.0) & 2316.5(1653.0) & 360.0(240.0) \\ \text { Widowed } & 26.0(5.9) & 891.0(990.0) & 160.0(720.0) & 0.0(1080.0) & 1653.0(3420.0) & 360.0(240.0) \\ & & & & & & \end{array}$

